\title{
Impaired skeletal muscle mitochondrial function in morbidly obese patients is normalized one year after bariatric surgery.
}

Citation for published version (APA):

Vijgen, G. H. E. J., Bouvy, N. D., Hoeks, J., Wijers, S., Schrauwen, P., \& van Marken Lichtenbelt, W. D. (2013). Impaired skeletal muscle mitochondrial function in morbidly obese patients is normalized one year after bariatric surgery. Surgery for Obesity and Related Diseases, 9(6), 936-941. https://doi.org/10.1016/j.soard.2013.03.009

Document status and date:

Published: 01/01/2013

DOI:

10.1016/j.soard.2013.03.009

Document Version:

Publisher's PDF, also known as Version of record

Document license:

Taverne

Please check the document version of this publication:

- A submitted manuscript is the version of the article upon submission and before peer-review. There can be important differences between the submitted version and the official published version of record.

People interested in the research are advised to contact the author for the final version of the publication, or visit the DOI to the publisher's website.

- The final author version and the galley proof are versions of the publication after peer review.

- The final published version features the final layout of the paper including the volume, issue and page numbers.

Link to publication

\footnotetext{
General rights rights.

- You may freely distribute the URL identifying the publication in the public portal. please follow below link for the End User Agreement:

www.umlib.nl/taverne-license

Take down policy

If you believe that this document breaches copyright please contact us at:

repository@maastrichtuniversity.nl

providing details and we will investigate your claim.
}

Copyright and moral rights for the publications made accessible in the public portal are retained by the authors and/or other copyright owners and it is a condition of accessing publications that users recognise and abide by the legal requirements associated with these

- Users may download and print one copy of any publication from the public portal for the purpose of private study or research.

- You may not further distribute the material or use it for any profit-making activity or commercial gain

If the publication is distributed under the terms of Article $25 \mathrm{fa}$ of the Dutch Copyright Act, indicated by the "Taverne" license above, 
Original article

\title{
Impaired skeletal muscle mitochondrial function in morbidly obese patients is normalized one year after bariatric surgery
}

\author{
Guy H.E.J. Vijgen, M.D. ${ }^{\mathrm{a}, \mathrm{b}, *}$, Nicole D. Bouvy, M.D., Ph.D. ${ }^{\mathrm{a}}$, Joris Hoeks, Ph.D. ${ }^{\mathrm{b}}$,
} Sander Wijers, Ph.D. ${ }^{b}$, Patrick Schrauwen, Ph.D. ${ }^{b}$, Wouter D. van Marken Lichtenbelt, Ph.D. ${ }^{b}$

${ }^{a}$ Department of Surgery, Maastricht University Medical Centre, Maastricht, the Netherlands

${ }^{b}$ Department of Human Biology, School for Nutrition, Toxicology and Metabolism, NUTRIM, Maastricht, the Netherlands

Received January 7, 2013; accepted March 22, 2013

\begin{abstract}
Background: Obesity and type 2 diabetes are associated with impaired skeletal muscle mitochondrial metabolism. As an intrinsic characteristic of an individual, skeletal muscle mitochondrial dysfunction could be a risk factor for weight gain and obesity-associated co-morbidities, such as type 2 diabetes. On the other hand, impaired skeletal muscle metabolism could be a consequence of obesity. We hypothesize that marked weight loss after bariatric surgery recovers skeletal muscle mitochondrial function.

Methods: Skeletal muscle mitochondrial function as assessed by high-resolution respirometry was measured in 8 morbidly obese patients (body mass index [BMI], $41.3 \pm 4.7 \mathrm{~kg} / \mathrm{m}^{2}$; body fat, $48.3 \% \pm 5.2 \%$ ) before and 1 year after bariatric surgery (mean weight loss: $35.0 \pm 8.6 \mathrm{~kg}$ ). The results were compared with a lean (BMI $22.8 \pm 1.1 \mathrm{~kg} / \mathrm{m}^{2}$; body fat, $15.6 \% \pm 4.7 \%$ ) and obese (BMI $33.5 \pm 4.2 \mathrm{~kg} / \mathrm{m}^{2}$; body fat, $34.1 \% \pm 6.3 \%$ ) control group.

Results: Before surgery, adenosine diphosphate (ADP)-stimulated (state 3) respiration on glutamate/succinate was decreased compared with lean patients $\left(9.5 \pm 2.4\right.$ versus $15.6 \pm 4.4 \mathrm{O}_{2}$ flux/ mtDNA; $P<.05)$. One year after surgery, mitochondrial function was comparable to that of lean controls (after weight loss, $12.3 \pm 5.5$; lean, $15.6 \pm 4.4 \mathrm{O}_{2}$ flux/mtDNA). In addition, we observed an increased state 3 respiration on a lipid substrate after weight loss $(10.0 \pm 3.2$ versus $14.0 \pm 6.6$ $\mathrm{O}_{2}$ flux/mtDNA; $\left.P<.05\right)$.

Conclusion: We conclude that impaired skeletal muscle mitochondrial function is a consequence of obesity that recovers after marked weight loss. (Surg Obes Relat Dis 2013;9:936-941.) (C) 2013 American Society for Metabolic and Bariatric Surgery. All rights reserved.
\end{abstract}

Keywords: $\quad$ Morbid obesity; Weight loss; Skeletal muscle mitochondrial function; Gastric banding

Obesity is one of the Western world's primary healthcare issues, and the increasing incidence of obesity is accompanied by an equal rise in co-morbidities such as type 2 diabetes, dyslipidemia, and hepatosteatosis [1]. The excess amount of adipose tissue in obesity is associated with a dysfunction in several tissues; hepatosteatosis, which causes

\footnotetext{
*Correspondence: Guy H.E.J. Vijgen, M.D., Department of Human Biology, Department of Surgery, Maastricht University Medical Centre, P Debyelaan 25, 6200 MD, Maastricht, the Netherlands.

E-mail: guy.vijgen@gmail.com
}

impaired liver function and increased lipid deposition in skeletal muscle, is suggested to induce insulin resistance $[1,2]$. In skeletal muscle from obese and obese type 2 diabetic patients, a decreased mitochondrial function compared with lean and nondiabetic patients has been reported. This could exacerbate the negative effect of intramyocellular lipid (IMCL) accumulation on insulin sensitivity [3-7]. However, although diet-induced weight loss decreased intramyocellular lipid content and has been shown to improve skeletal muscle insulin sensitivity in nondiabetic overweight patients [8,9], skeletal muscle 
mitochondrial function (as determined by nicotinamide adenine dinucleotide [NADH] oxidase enzyme levels) per se did not change $[8,10]$. This may suggest that reduced mitochondrial function in obesity is an intrinsic characteristic of obese patients. However, it should be noted that weight loss in the aforementioned studies was low (9-18 $\mathrm{kg}$ ) [8-10] in comparison to that after bariatric surgery (37$42 \mathrm{~kg}$ ) [11], and it cannot be excluded that further weight reduction does improve skeletal muscle mitochondrial metabolism. Indeed, it has been shown before that proteins associated with mitochondrial biogenesis in skeletal muscle were enhanced and related to improved insulin sensitivity after bariatric surgery, suggesting that skeletal muscle mitochondrial function may be suppressed by excessive weight [12,13]. However, to our knowledge no study has evaluated the effect of bariatric surgery on skeletal muscle mitochondrial function per se, and therefore these findings need further confirmation. To test our hypothesis that skeletal muscle mitochondrial function improves after bariatric surgery, we investigated ex vivo skeletal muscle mitochondrial function in morbidly obese patients before and 1 year after laparoscopic adjustable gastric banding (LAGB) surgery and compared these findings with those of an obese and lean control cohort.

\section{Materials and methods}

\section{Study protocol}

Approval was obtained from the Maastricht University Medical Centre institutional review board. Written informed consent was received before the first muscle biopsy from 2 male and 6 female morbidly obese patients who were awaiting laparoscopic adjustable gastric banding (LAGB), with a mean body mass index (BMI) of $41.3 \pm 4.7 \mathrm{~kg} / \mathrm{m}^{2}$ (Table 1). One female subject took levothyroxine for hypothyroidism and was euthyroid for several years. Diabetes mellitus was an exclusion criterion. Skeletal muscle mitochondrial function of the 8 morbidly obese patients before and after weight loss was compared with that of 10 healthy lean male and 10 healthy obese male control patients (Table 1). These reference patients were studied by our group before; however, current results for skeletal muscle mitochondrial function were not reported previously [14].

\section{Body composition}

Body composition (fat free mass, fat mass) was determined under fasted conditions by dual X-ray absorptiometry (DXA, type Discovery A, Hologic, Bedford, MA).

\section{Muscle biopsies}

Several weeks before surgery, a muscle biopsy according to Bergström et al. [15] was taken under fasted conditions at about 8:30 AM. Part of the muscle was directly used for the fresh preparation of permeabilized muscle fibers as described [3]. The remaining part of the muscle was directly frozen in liquid nitrogen and stored at $-80^{\circ} \mathrm{C}$ until further analysis.

To determine skeletal muscle mitochondrial capacity, high-resolution respirometry was performed in permeabilized muscle fibers at $37^{\circ} \mathrm{C}$ in a 2-chamber-Oxygraph (OROBOROS Instruments, Innsbruck, Austria).

\section{High-resolution respirometry protocol}

Coupled (state 3) respiration, initiated by addition of 2 mM ADP, was measured for complex I-linked substrate combination malate + glutamate, both in the presence and absence of the lipid substrate octanoyl-carnitine. Coupled respiration was then maximized with convergent electron input through complex I and complex II, by adding saturating concentrations of succinate $(10 \mathrm{mM})$. Subsequently, mitochondrial respiration uncoupled from adenosine triphosphate (ATP) synthesis (state 4) was determined via addition of the ATP-synthase inhibitor oligomycin. In addition, the chemical uncoupler FCCP [carbonyl-cyanide-4-(trifluoromethoxy)-phenylhydrazone] was used to

Table 1

Subject characteristics for 2 male and 6 female morbidly obese patients before (MO-before) and after (MO-after) weight loss compared with 10 male obese (obese) and 10 male lean (lean) control patients.

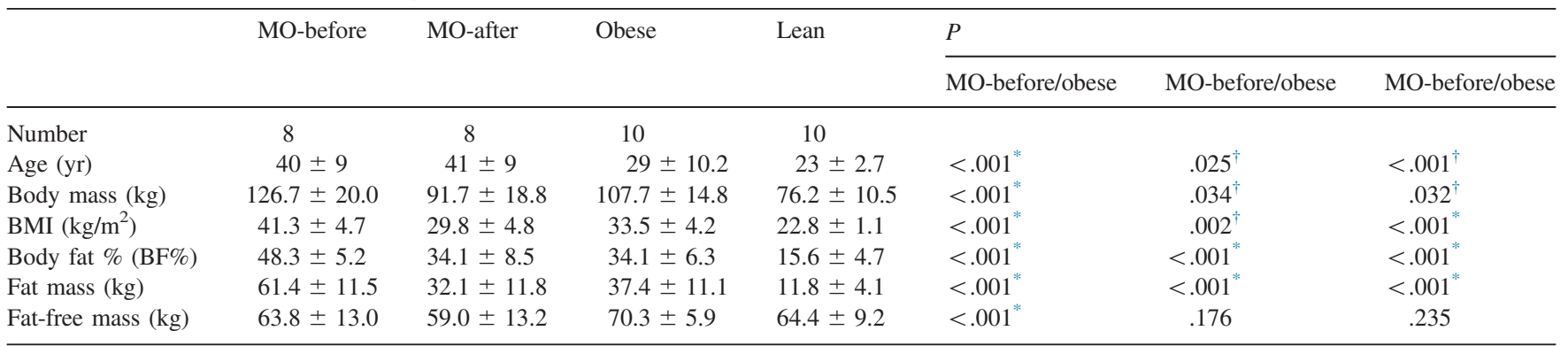

\footnotetext{
$\mathrm{BMI}=$ body mass index; $\mathrm{MO}=$ morbidly obese

${ }^{*} P<.001$.

${ }^{\dagger} P<.05$.
} 
maximize oxygen flux to assess maximal mitochondrial capacity (state $\mathrm{u}$ respiration).

\section{Normalization for mitochondrial DNA content}

To determine mitochondrial density, the mitochondrial DNA (mtDNA) copy numbers were determined according to Phielix et al. [3], and all muscle biopsy samples were run in one analysis. For comparison, oxygen fluxes per wetweight muscle mass were normalized for mtDNA. The mitochondrial DNA copy numbers did not differ significantly before and after weight loss (mtDNA copy number, $960.6 \pm 425.1$ before, $868.8 \pm 386.0$ after weight loss; $P=.371$ ). All results showed similar trends and significance when oxygen fluxes were not corrected for mtDNA (results not shown). Oxygen fluxes $\left(\mathrm{O}_{2}\right.$ flux) shown are expressed as picomoles $\mathrm{O}_{2} \times$ seconds $^{-1} \times$ milligrams of tissue $^{-1} \times$ mtDNA $\times 10^{6}$.

\section{Plasma values}

Plasma thyroid-stimulating hormone (TSH) and free thyroxine $\left(\mathrm{FT}_{4}\right)$ were measured using an electrochemiluminescence immunoassay (Roche, Basel, Switzerland) and a fluoroimmunoassay (PerkinElmer, Waltham, MA). Plasma insulin, glucose, free fatty acids (FFA), and the homeostasis model of assessment-insulin resistance (HOMA-IR) were calculated as described [14].

\section{Follow-up}

All 8 patients underwent LAGB without any perioperative or postoperative complications. One year after LAGB a second muscle biopsy was taken.

\section{Statistical analysis}

Reported data were expressed as means \pm SD. Statistical analyses were performed with PASW Statistics 18.0 for Mac OS 10.6.4. Repeated measurements before and 1 year after bariatric surgery were compared using paired Student's $t$ tests. Comparisons between groups (morbidly obese patients before and after bariatric surgery, obese and lean control patients) were made using a one-way ANOVA with a post hoc Bonferroni correction. A $P$ value $<.05$ was considered significant.

\section{Results}

Body composition was significantly altered 1 year after surgery (Table 1), with a mean weight loss of $27.9 \% \pm 6.6 \%$. After a mean follow-up of 18 months, there was no difference in body composition compared with the 1-year time point (body mass $91.7 \pm 18.8$ versus $91.5 \pm 18.3 \mathrm{~kg} ; \quad$ BMI $29.8 \pm 4.8$ versus $29.7 \pm 4.7 \mathrm{~kg} / \mathrm{m}^{2} ; P=.844$ ), which indicates patients were weight stable at the moment of the second muscle biopsy.

ADP-stimulated (state 3) respiration increased after weight loss upon complex I-linked substrates (for malate + glutamate $4.2 \pm 1.4$ versus $6.8 \pm 2.0 \mathrm{O}_{2}$ flux; $P=.029$; for malate + octanoyl-carnitine + glutamate [MOG] $4.2 \pm 2.1$ versus $8.9 \pm 4.2 \mathrm{O}_{2}$ flux; $P=.028$ ) as well as upon parallel electron input into both complex I and complex II (for malate + octanoyl-carnitine + glutamate + succinate $[\mathrm{MOGS}] 10.0 \pm 3.2$ versus $14.0 \pm 6.6 \mathrm{O}_{2}$ flux; $P=.031$ ), although did this not reach statistical significance for malate + glutamate + succinate (MGS; $9.5 \pm 2.4$ versus $12.3 \pm 5.5 \mathrm{O}_{2}$ flux; $P=.086$; Fig. 1). Leak respiration upon the ATP-synthase inhibitor oligomycin (i.e., respiration not related to ATP synthesis; state 4 respiration) was determined as a marker for mitochondrial uncoupling but remained unaffected by weight loss $\left(6.1 \pm 2.7\right.$ versus $5.4 \pm 2.4 \mathrm{O}_{2}$ flux; $P=.093$; Fig. 1). The relative contribution of state 4 to state 3 respiration (uncoupling ratio [UCR]) decreased significantly after weight loss $(0.6 \pm 0.2$ versus $.4 \pm 0.1 ; P=.049$; Fig. 1$)$.

Maximally uncoupled mitochondrial respiration, as analyzed after addition of FCCP in the presence of octanoylcarnitine, did not increase significantly after weight loss $\left(15.0 \pm 4.4\right.$ versus $18.0 \pm 8.2 \mathrm{O}_{2}$ flux; $P=.212$; Fig. 1$)$.

State 3 respiration upon complex I and II substrates MGS in muscle fibers was significantly lower in morbidly obese patients before bariatric surgery compared with lean patients $\left(9.5 \pm 2.4\right.$ versus $15.6 \pm 4.4 \mathrm{O}_{2}$ flux; $\left.P=.028\right)$ and tended to be lower compared with obese controls $(9.5 \pm 2.4$ versus $13.7 \pm 5.8 \mathrm{O}_{2}$ flux; $P=.076$; Fig. 2). State 4 leak respiration was not different for morbidly obese compared with lean and obese controls (MO-before $6.1 \pm 2.7$; lean $4.7 \pm 1$; obese $3.9 \pm 1.5 \mathrm{O}_{2}$ flux; $P=.127$; Fig. 2). After weight loss, there were no statistically significant differences for both state 3 and state 4 respiration for morbidly obese patients (MO-after) compared with lean and obese controls (state 3: MO-after $12.3 \pm 5.5$; lean $15.6 \pm 4.4$; obese $13.7 \pm 5.8 \mathrm{O}_{2}$ flux; $P=.411$; state 4 : MO-after $5.4 \pm 2.4$; lean $4.7 \pm 1.6$; obese $3.9 \pm 1.5 \mathrm{O}_{2}$ flux; $P=$ .210 ; Fig. 2). Although there were significant age differences between the morbidly obese and lean and obese control groups (Table 1), there was no relation between state 3 or state 4 respiration and age (state 3: $P=.910$; state 4: $P=.610)$.

\section{Discussion}

In this study, we investigated the effect of pronounced weight loss induced by bariatric surgery on skeletal muscle mitochondrial function in morbidly obese patients. ADPstimulated (state 3 ) respiration increased significantly 1 year after bariatric surgery. Our data suggest that impaired skeletal muscle mitochondrial function in morbidly obese 

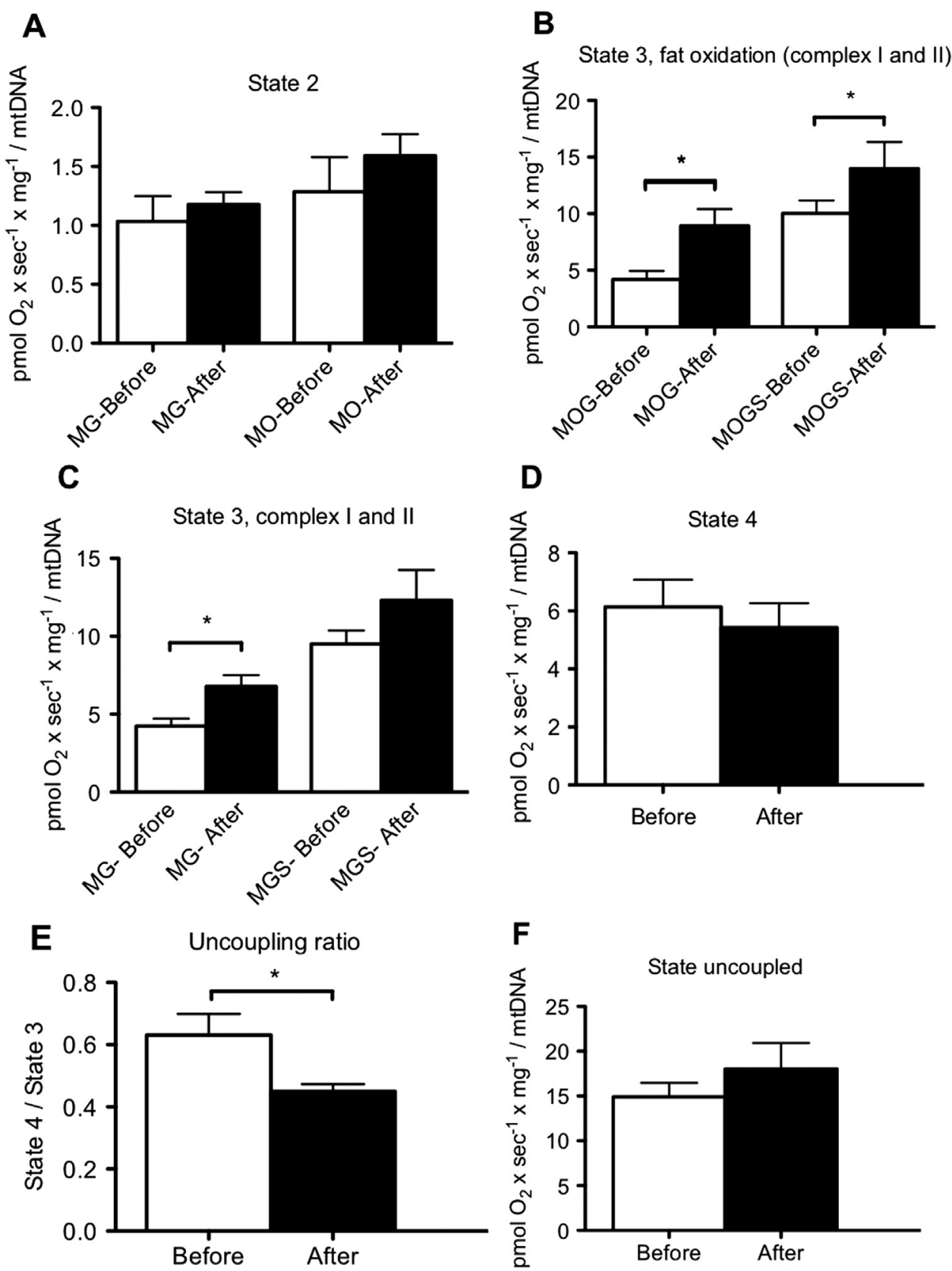

Fig. 1. Skeletal muscle fiber respirometry before (white bars) and after (black bars) weight loss. (A) Oxygen consumption in the presence of endogenous substrates (state 2 respiration) was similar before and after weight loss $(P=.310)$. (B) Adenosine diphosphate (ADP)-stimulated state 3 respiration upon a lipid substrate for complex I (malate + octanoyl-carnitine + glutamate $[\mathrm{MOG}]$ and complex I and II substrates (malate + octanoyl-carnitine + glutamate + succinate [MOGS]). (C) State 3 respiration upon complex I substrates (malate + glutamate [MG]) and complex I and II substrates (malate + glutamate + succinate $[\mathrm{MGS}]$ ). (D) Leak (state 4) respiration obtained by addition of the ATP-synthase inhibitor oligomycin. (E) The relative contribution of state 4 to state 3 respiration (uncoupling ratio [UCR]). (F) Maximal respiration upon carbonyl-cyanide-4-(trifluoromethoxy)-phenylhydrazone (FCCP) (state uncoupled). $\mathrm{O}_{2}$ flux shown: picomoles $\mathrm{O}_{2}$ consumption $\times$ seconds $^{-1} \times$ milligrams of tissue $\mathrm{e}^{-1} \times \mathrm{mtDNA} \times 10^{6}$. Values shown are mean $+\mathrm{SEM}, \mathrm{n}=8 .{ }^{*} P<.05$.

patients is reversible by bariatric surgery-induced weight loss.

Skeletal muscle fat oxidation is negatively related to BMI [16], resulting in an increased muscle fat accumulation in obesity $[9,17]$. This impaired lipid oxidation is associated with skeletal muscle insulin resistance and thus suggests a pathophysiologic basis for obesity-related type 2 diabetes
[9]. In line with this notion, skeletal muscle mitochondria from obese type 2 diabetic patients displayed a reduced activity of the mitochondrial oxidative enzyme NADHreductase, suggesting an impairment of mitochondrial function [5], which was confirmed by in vivo measurements [18]. Furthermore, a detailed ex vivo analysis of mitochondrial function in permeabilized skeletal muscle fibers 

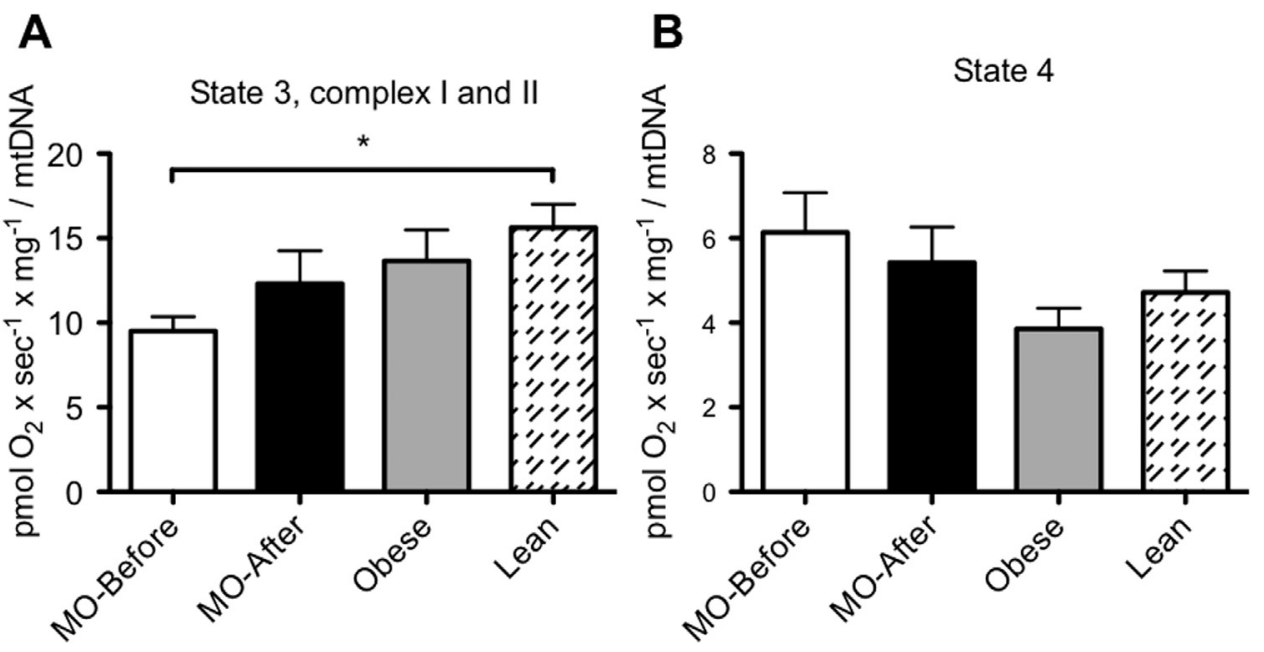

Fig. 2. Comparison between skeletal muscle mitochondrial function for morbidly obese patients before (MO-before) and after (MO-after) weight loss and lean and obese controls. (A) Adenosine diphosphate (ADP)-stimulated state 3 respiration upon complex I and II substrates malate, glutamate, and succinate. (B) Mitochondrial state 4 respiration after addition of oligomycin. $\mathrm{O}_{2}$ flux shown: picomoles $\mathrm{O}_{2}$ consumption $\times$ seconds $^{-1} \times$ milligrams of tissue ${ }^{-1} \times$ mtDNA $\times 10^{6}$. Values shown are mean + SEM. ${ }^{*} P<.05$.

showed that the observed in vivo mitochondrial dysfunction in overweight type 2 diabetes (mean BMI $28.9 \mathrm{~kg} / \mathrm{m}^{2}$ ) was associated with a decreased intrinsic mitochondrial capacity, that is, ADP-stimulated (state 3) mitochondrial respiration corrected for mitochondrial density [3]. Skeletal muscle mitochondrial state 3 respiration was also reported to be reduced in nondiabetic morbidly obese patients eligible for bariatric surgery (mean BMI $40 \mathrm{~kg} / \mathrm{m}^{2}$ ) compared with that for lean controls [6]. To observe whether obesity is causative for a decreased mitochondrial function, several reports have studied the effect of weight loss on skeletal muscle mitochondrial function, in both type 2 diabetic and nondiabetic patients. A diet-induced weight loss of $10.6 \mathrm{~kg}$ did not induce changes in mitochondrial NADH-reductase activity in nondiabetic obese patients (mean BMI before weight loss $33.4 \mathrm{~kg} / \mathrm{m}^{2}$ ) [8], and 1 report even observed a decrease in mitochondrial cytochrome c oxidase activity after weight loss (12-17 kg weight loss; initial BMI $33-34 \mathrm{~kg} / \mathrm{m}^{2}$ ) [10]. In contrast, after a more pronounced diet-induced weight loss in nondiabetic patients (13-32 kg weight loss; initial BMI $33.8 \mathrm{~kg} / \mathrm{m}^{2}$ ), an improved oxidative enzyme (succinate dehydrogenase) activity was observed [19].

Bariatric surgery results in pronounced weight loss, and after Roux-en-Y gastric bypass and biliopancreatic diversion surgery (42-63 kg weight loss; mean initial BMI 45.9$53.5 \mathrm{~kg} / \mathrm{m}^{2}$ ), proteins associated with mitochondrial biogenesis (PGC1 $\alpha$ and MFN2) were enhanced in skeletal muscle and related to improved insulin sensitivity as assessed by euglycemic-hyperinsulinemic clamp [12,13]. Finally, in patients with an approximate 50-kg weight loss after Roux-en-Y gastric bypass, skeletal muscle fatty acid oxidation (as assessed ex vivo with ${ }^{14} \mathrm{C}$-palmitate) did not change and was decreased compared with lean controls [20]. However, the postoperative BMI was relatively high $\left(36.5 \mathrm{~kg} / \mathrm{m}^{2}\right)$ compared with that of the present study $\left(30 \mathrm{~kg} / \mathrm{m}^{2}\right)$.

In contrast to the aforementioned weight loss studies using biochemical assessments of mitochondrial enzyme activities to assess skeletal muscle mitochondrial function,

Table 2

Plasma values before and after weight loss.

\begin{tabular}{|c|c|c|c|c|c|c|c|}
\hline & \multirow[t]{2}{*}{ MO-before } & \multirow[t]{2}{*}{ MO-after } & \multirow[t]{2}{*}{ Obese } & \multirow[t]{2}{*}{ Lean } & \multicolumn{3}{|l|}{$P$} \\
\hline & & & & & MO-before/MO-after & MO-before/obese & MO-after/lean \\
\hline TSH (mU/mL) & $2.0 \pm .7$ & $1.9 \pm .4$ & - & - & .341 & - & - \\
\hline $\mathrm{FT}_{4}(\mathrm{pmol} / \mathrm{L})$ & $13.5 \pm 2.0$ & $14.9 \pm 1.4$ & - & - & $.009^{*}$ & - & - \\
\hline Glucose (mM) & $4.9 \pm .4$ & $5.2 \pm 1.0$ & $5.4 \pm .4$ & $5.0 \pm .2$ & .199 & $.016^{*}$ & .436 \\
\hline Insulin $(\mu \mathrm{U} / \mathrm{mL})$ & $25.4 \pm 8.5$ & $16.6 \pm 5.2$ & $17.3 \pm 5.4$ & $10.0 \pm 2.3$ & .064 & $.028^{*}$ & $.009^{*}$ \\
\hline HOMA-IR & $4.9 \pm 2.9$ & $3.8 \pm 1.1$ & $4.2 \pm 1.5$ & $2.2 \pm .5$ & .324 & .134 & $.005^{*}$ \\
\hline FFA $(\mu \mathrm{M})$ & $588.3 \pm 234.3$ & $567.0 \pm 283.4$ & $280.1 \pm 128.1$ & $259.0 \pm 84.4$ & .750 & $.003^{*}$ & $.005^{*}$ \\
\hline
\end{tabular}

$\mathrm{FFA}=$ free fatty acids; $\mathrm{FT}_{4}=$ free thyroxine; HOMA-IR = homeostasis model assessment-insulin resistance; TSH $=$ thyroid-stimulating hormone.

Values shown for 2 male and 6 female morbidly obese patients before (MO-before) and after (MO-after) weight loss compared with 10 male obese (obese) and 10 male lean (lean) control patients.

${ }^{*} P<.05$. 
we performed a detailed characterization of mitochondrial function via ex vivo mitochondrial respiration in permeabilized muscle fibers. In this study, we show ADPstimulated state 3 respiration increased after a mean $35-\mathrm{kg}$ weight loss and restored to normal levels. The mitochondrial density (as assessed by mtDNA copy numbers) did not change after weight loss and therefore the observed improvement in mitochondrial respiration is an intrinsic mitochondrial characteristic. The improvement in muscle mitochondrial metabolism up to levels comparable to those of lean control patients suggests that the observed weight loss could "restore" obesity-induced impairments in skeletal muscle mitochondrial function. Further studies should elucidate the molecular and clinical changes associated with the increase skeletal muscle mitochondrial function. All included morbidly obese patients were nondiabetic, and plasma values (Table 2) for plasma insulin showed a nearly significant decrease $(P=.064)$. However, the HOMA-IR did not change after weight loss $(P=.324)$. Although fasting insulin levels tended to be lower after weight loss (mean reduction 28.6\%) further studies in morbidly obese diabetic populations are necessary to determine the effect of weight loss on skeletal muscle mitochondrial function and its relation to obesity-induced insulin resistance.

\section{Conclusion}

This study shows an increase in ex vivo skeletal muscle mitochondrial function in morbidly obese patients 1 year after LAGB-induced weight loss. The level of weight loss in this study was higher than previous reports that did not observe differences in mitochondrial function after weight loss. Possibly, the very pronounced weight loss after bariatric surgery is necessary to recover mitochondrial function in morbid obesity.

\section{Acknowledgments}

This work is part of the research program TOP-subsidies (Netherlands Science Foundation ZonMw, TOP 91209037 to W. van Marken Lichtenbelt), which is partly financed by the Netherlands Organization for Scientific Research. A VICI (grant 918.96.618) for innovative research from the Netherlands Organization for Scientific Research supports the work of P. Schrauwen.

We thank Esther Moonen-Kornips for analyzing skeletal muscle mitochondrial DNA and Jos Stegen for biochemical analysis of plasma values. We thank Maarten Vosselman and Marc Schreinemacher for practical help with the muscle biopsies and Esther Phielix for supervision during the highresolution respirometry.

\section{Disclosures}

The authors have no commercial associations that might be a conflict of interest in relation to this article.

\section{References}

[1] Haslam DW, James WP. Obesity. Lancet 2005;366:1197-209.

[2] Timmers S, Schrauwen P, de Vogel J. Muscular diacylglycerol metabolism and insulin resistance. Physiol Behav 2008;94:242-51.

[3] Phielix E, Schrauwen-Hinderling VB, Mensink M, et al. Lower intrinsic ADP-stimulated mitochondrial respiration underlies in vivo mitochondrial dysfunction in muscle of male type 2 diabetic patients. Diabetes 2008;57:2943-9.

[4] Boyle KE, Zheng D, Anderson EJ, Neufer PD, Houmard JA. Mitochondrial lipid oxidation is impaired in cultured myotubes from obese humans. Int J Obes (Lond) 2012;36:1025-31.

[5] Kelley DE, He J, Menshikova EV, Ritov VB. Dysfunction of mitochondria in human skeletal muscle in type 2 diabetes. Diabetes 2002;51:2944-50.

[6] Bakkman L, Fernstrom M, Loogna P, Rooyackers O, Brandt L, Lagerros YT. Reduced respiratory capacity in muscle mitochondria of obese subjects. Obes Facts 2010;3:371-5.

[7] Schrauwen P, Schrauwen-Hinderling V, Hoeks J, Hesselink MK. Mitochondrial dysfunction and lipotoxicity. Biochim Biophys Acta 2010;1801:266-71.

[8] Toledo FG, Menshikova EV, Azuma K, et al. Mitochondrial capacity in skeletal muscle is not stimulated by weight loss despite increases in insulin action and decreases in intramyocellular lipid content. Diabetes 2008;57:987-94.

[9] Kelley DE, Goodpaster B, Wing RR, Simoneau JA. Skeletal muscle fatty acid metabolism in association with insulin resistance, obesity, and weight loss. Am J Physiol 1999;277:E1130-41.

[10] Simoneau JA, Veerkamp JH, Turcotte LP, Kelley DE. Markers of capacity to utilize fatty acids in human skeletal muscle: relation to insulin resistance and obesity and effects of weight loss. FASEB J 1999;13:2051-60.

[11] Buchwald H, Avidor Y, Braunwald E, et al. Bariatric surgery: a systematic review and meta-analysis. JAMA 2004;292:1724-37.

[12] Gastaldi G, Russell A, Golay A, et al. Upregulation of peroxisome proliferator-activated receptor gamma coactivator gene (PGC1 A) during weight loss is related to insulin sensitivity but not to energy expenditure. Diabetologia 2007;50:2348-55.

[13] Hernandez-Alvarez MI, Chiellini C, Manco M, et al. Genes involved in mitochondrial biogenesis/function are induced in response to biliopancreatic diversion in morbidly obese individuals with normal glucose tolerance but not in type 2 diabetic patients. Diabetologia 2009;52:1618-27.

[14] Wijers SL, Saris WH, van Marken Lichtenbelt WD. Cold-induced adaptive thermogenesis in lean and obese. Obesity (Silver Spring) 2010;18:1092-9.

[15] Bergstrom J, Hermansen L, Hultman E, Saltin B. Diet, muscle glycogen and physical performance. Acta Physiol Scand 1967;71: $140-50$.

[16] Kim JY, Hickner RC, Cortright RL, Dohm GL, Houmard JA. Lipid oxidation is reduced in obese human skeletal muscle. Am J Physiol Endocrinol Metab 2000;279:E1039-44.

[17] Boyle KE, Canham JP, Consitt LA, et al. A high-fat diet elicits differential responses in genes coordinating oxidative metabolism in skeletal muscle of lean and obese individuals. J Clin Endocrinol Metab 2011;96:775-81.

[18] Schrauwen-Hinderling VB, Kooi ME, Hesselink MK, et al. Impaired in vivo mitochondrial function but similar intramyocellular lipid content in patients with type 2 diabetes mellitus and BMI-matched control subjects. Diabetologia 2007;50:113-20.

[19] Kern PA, Simsolo RB, Fournier M. Effect of weight loss on muscle fiber type, fiber size, capillarity, and succinate dehydrogenase activity in humans. J Clin Endocrinol Metab 1999;84:4185-90.

[20] Berggren JR, Boyle KE, Chapman WH, Houmard JA. Skeletal muscle lipid oxidation and obesity: influence of weight loss and exercise. Am J Physiol Endocrinol Metab 2008;294:E726-32. 